\title{
Possibilities of applying motif group parameters for description roughness of turned surfaces
}

\author{
Maciej Kowalski ${ }^{1, *}$, Magdalena Wiśniewska ${ }^{1}$, Paweł Karolczak $^{1}$, Jozef Holubjak ${ }^{2}$ \\ ${ }^{1}$ Wrocław University of Science and Technology, Faculty of Mechanical Engineering. \\ ul. Łukasiewicza 5, 50-371 Wrocław, Poland \\ ${ }^{2}$ University of Žilina, Faculty of Mechanical Engineering, Univerzitna 1, 010 26, Žilina, Slovakia
}

\begin{abstract}
This article explores the methodology of assessing the applicability of roughness parameters from the motif group to the evaluation of one-way and periodic geometrical surface structures. The results of surface roughness measurements of aluminum samples turned with variable kinematic parameters were presented. Usability of using surface motifs in combination with selected parameters described in ISO standards for assessment of geometrical structures characteristic for longitudinal turning was shown.
\end{abstract}

Keywords: aluminum alloys, surface geometrical structure, roughness parameters

\section{Introduction}

In modern manufacturing techniques the main goal is to achieve good, repeatable quality of products. One of the main problems associated with this is the quality of the surface layer of machined object. It combines whole of issues related to methods of surface manufacturing fulfilling specific operation requirements.

Characterizing surface roughness is currently taking a lot of significance in many areas related to the construction, technology and operation of machines and devices. Currently applied methodology of surface roughness analysis was developed around 1970. Since then, over the years, nearly 300 different roughness and waviness parameters were offered to the users [1]. In 90s of the last century, trend for creating new roughness parameters was called "rash of parameters" or "parametric fever"[2]. A large number of defined and possible to use roughness and waviness parameters makes it impossible to give the value to all of them. On the other hand, the complexity of the geometric structure of the surface means that use the one, selected parameter does not give full knowledge about its condition and even more about its operational capabilities [3]. Therefore a few, suitably selected parameters should be used to description of the usable surface state. Because there are no standards or procedures that would inform when and in what cases given parameters should be used, the selection should be representative to given application. For each element to be manufactured, it is necessary to decide which features of the of the geometric structure of the surface are relevant and which roughness parameters correspond to them.

\footnotetext{
* Corresponding author: maciej.kowalski@pwr.edu.pl

Reviewers: Mária Čilliková, Michal Hatala
} 
In industry, the $R a$ parameter is most commonly used parameter. It is given very often in connection with the description of surface machining method by which it can be obtained. If production conditions are stabilized this type of evaluation makes it possible to maintain constant, within defined limits, surface roughness characteristics. It is due to quite strong statistical associations between parameters describing different profile features for surfaces machined in similar conditions. In case of the parts operating under specific conditions and determining the functional characteristics of the entire product e.g. the surface of the exhaust fins of internal combustion engines, two or more roughness parameters are used to assess the surface [4].

Another important aspect increasing the possibilities of describing surface geometrical conditions are differences in the standards regarding surface roughness used in individual countries. Universal globalization however means that many standards have been unified and the most universal are being pursued. Differences, however, remain. An example here can be the so - called French methods for roughness calculating. They were created for the French automotive industry at the beginning of 80 s of the last century. In Poland they are called motif method.

\subsection{Motifs method}

This method relies on division primary profile into so - called motifs. According to the norm motif is concluded between the highest points of two locals not necessarily neighboring peaks of the profile (fig.1) Motif is characterized by:

- $\quad$ its length $A R$ or $A W$ measured parallel to direction of primary profile ,

- $\quad$ its two depths $H_{j}$ i $H_{j+l}$ measured perpendicularly to direction of primary profile,

- $\quad$ its characteristic depth $T$, which is the lower depth of this two $\left(T=\min \left(H_{j}, H_{j+1}\right)\right.$.

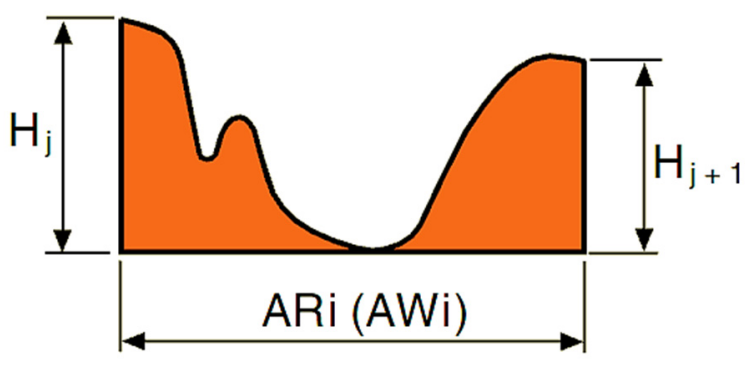

Fig. 1. Roughness motif

Fragments received this way are next joined according to specific rules among which following conditions are distinguished: envelope, length, magnification and equality $[5,6]$.

Envelope condition - concerns peaks which are higher than neighboring ones. Joint peak of two neighboring motifs must be smaller or equal from one of adjacent peak.

Length condition - concerns limitation of length of one motif to the limit value A (conventional boundary between roughness and waviness) or limit value B (conventional boundary between waviness and shape deviations). Sum of the length of two adjacent motifs $A R_{i}+A R_{i+1}$ have to be smaller or equal to $\mathrm{A}$ for roughness and $A W_{i}+A W_{i+1}<B$ for waviness.

Magnification condition - concerns suppression of the smallest peaks however the greatest possible motifs are sought - after. This condition prevents combining of two motifs when its characteristic depth $T$ is smaller than depth of one of the two initial motifs. The 
effect of this is suppression of the smaller peak lying between large ones. Motifs can be combined only if the characteristic depth $T$ of the created motif is greater or equal to both depths characteristic for component motifs.

Equality condition - prevents combination of motifs with similar depths that occur for example with periodic profiles. Prevents suppression of motifs which depth is similar to depth of adjacent one. The combination of the motifs in this calculation method should be used until all possible further combinations are exhausted. Motifs can be combined only when one of the depths is smaller or equal to $60 \%$ of the characteristic depth $T$ of the tested connected motif.

Knowing the conditions for combining motifs it is possible to proceed of calculating parameters from motif group. In this work four of them were designated (fig. 2):

$P t$ - sum of the height of the highest profile peak $Z p$ and depth of the lowest valley $Z v$ profile inside evaluation length $l n$

$R$ - arithmetic mean of the depth value $H_{j}$ of roughness motifs inside evaluation length which value is calculated from the formula 1 :

$$
R=\frac{1}{m} \sum_{j=1}^{m} H_{j}
$$

$R x$ - the largest depth $H_{j}$ from all the roughness motifs inside the evaluation length.

$A R$ - the arithmetic mean of the length value $A R_{i}$ of roughness motifs inside evaluation length

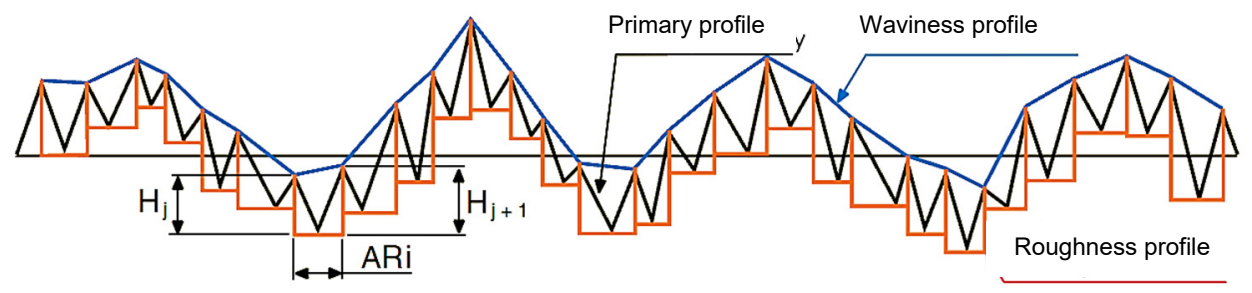

Fig. 2. Graphic description of parameters $R, R x, A R$

The undoubted advantages of the motif method are: no need to apply filtration, a small number of parameters and mapping of each local peak on the elevation at omitting those which are in profile valleys and which are not participating in contact of two surfaces cooperating with each other.

\section{Research methodology}

A shaft of aluminum alloy 7075 was tested. As a machining method turning was chosen. Research was carried out on a CNC TUR $560 \mathrm{MN}$ numerical lathe. For tests turning inserts TCGX16T304-Al H10 were used with uncoated cemented carbide and they were mounted in a holder marked STGCR 2020K16. The following cutting parameters were used: $v_{c}=105$; $210 ; 420 ; 530$ and $660 \mathrm{~m} \cdot \mathrm{min}^{-1} ; f=0.08 ; 0.19 ; 0.37 \mathrm{~mm}^{-\mathrm{rev}^{-1}}$. Depth of cut was $a_{p}=0.5 \mathrm{~mm}$.

Roughness measurements were conducted using Form Talysurf 120L tester (fig. 3) applying following settings: Gaussian digital filter, $\lambda c=0.8 \mathrm{~mm}, \lambda s=0.0025 \mathrm{~mm}$, bandwidth: 300:1. During calculating motif parameters following settings were used: shape: straight line LS, filter R \& W, $A=0.25 \mathrm{~mm}, B=1.4 \mathrm{~mm}, \lambda s=0.0025 \mathrm{~mm}$. For analysis of usefulness of motif method for description of examined surfaces, five amplitude parameters, apart from 
already described parameters from motif group, were chosen: $R a, R z, R p, R v, R q$, two statistical: $R k u, R s k$ and spatial: $R S m, R S$, as well as hybrid: $R \Delta a i R \Delta q$.

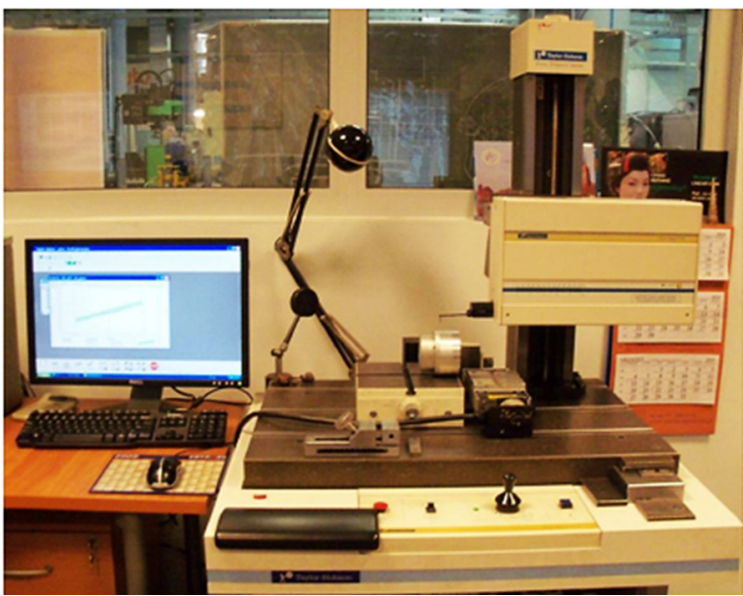

Fig. 3. Measuring stand-Form Talysurf-120L tester, Taylor Hobson Limited company

Two indicators were used for assess suitability of individual roughness parameters. First of them is the correlation coefficient $\rho$, which defines the level of linear relation between two variables. It is a quotient of covariance and the product of standard deviations of this variables what was shown on equation 2:

$$
\rho_{X Y}=\frac{\operatorname{cov}(X, Y)}{\sigma_{X} \sigma_{Y}}
$$

It is considered that when the correlation coefficient is equal 0 linear correlation does not exist but a curvilinear correlation may occur. The closer values to the number 1 or -1 will achieve correlation coefficient - the greater linear correlation will be. Above 0.9 and below -0.9 it is considered that very strong linear correlation occurs.

However, one should be aware of the fact of frequent over - interpretation connected with drawing conclusions only on the basis of the value of the correlation coefficient. Therefore to assess the suitability of use of roughness parameters from individual groups second indicator which defines significance level of change of characteristic profile feature was proposed [7,8]. It was marked with a symbol $t$. It is expressed in the percent and described with equation:

$$
t=\frac{R_{\max }-R_{\min }}{R_{\text {śr }}} * 100 \%
$$

where:

- $R_{\max }-$ maximum value of tested roughness parameter,

- $R_{\min }-$ minimum value of tested roughness parameter,

- $R_{\text {śr }}$ - average value of tested roughness parameter,

\section{Tests results}

Making qualification of suitability of a given roughness parameter for description of roughness changes, the closeness of the correlation coefficient $\rho$ to one was assumed and 
whether the level of significance of the change of tested parameter $t$ is greater than $30 \%$. Tables 1-4 presents surface roughness tests results along with calculated values of suitability indicators of the calculated parameters.

Table 1. Influence of the feed $f$ on values of selected amplitude roughness parameters 2D

\begin{tabular}{|c|c|c|c|c|c|c|c|c|c|}
\hline \multirow{2}{*}{\multicolumn{2}{|c|}{ Machining parameters }} & \multicolumn{8}{|c|}{ Roughness parameters } \\
\hline & & \multicolumn{5}{|c|}{ AMPLITUDE } & \multicolumn{3}{|c|}{ MOTIF } \\
\hline $\begin{array}{c}v_{c} \\
{\left[\mathrm{~m} \cdot \mathrm{min}^{-1}\right]}\end{array}$ & $\begin{array}{c}f \\
{\left[\mathrm{~mm}^{2} \cdot \mathrm{rev}^{-1}\right]}\end{array}$ & $R a$ & $R z$ & $R p$ & $R v$ & $R q$ & Pt & $R$ & $R x$ \\
\hline \multirow{3}{*}{105} & 0.08 & 0.53 & 2.989 & 1.569 & 1.42 & 0.64 & 3.863 & 1.95 & 3.21 \\
\hline & 0.19 & 1.183 & 5.896 & 3.298 & 2.598 & 1.407 & 6.82 & 4.796 & 6.276 \\
\hline & 0.37 & 4.946 & 19.235 & 12.414 & 6.820 & 5.667 & 21.976 & 9.436 & 21.076 \\
\hline \multirow{3}{*}{210} & 0.08 & 0.551 & 3.353 & 1.862 & 1.490 & 0.674 & 4.141 & 2.236 & 3.846 \\
\hline & 0.19 & 1.167 & 5.688 & 3.412 & 2.275 & 1.376 & 7.134 & 5.254 & 6.839 \\
\hline & 0.37 & 4.981 & 18.966 & 12.243 & 6.723 & 5.694 & 21.972 & 9.851 & 21.583 \\
\hline \multirow{3}{*}{420} & 0.08 & 0.521 & 3.399 & 2.030 & 1.368 & 0.643 & 5.473 & 2.169 & 4.41 \\
\hline & 0.19 & 0.559 & 3.564 & 2.112 & 1.451 & 0.713 & 6.897 & 2.113 & 5.813 \\
\hline & 0.37 & 4.917 & 19.256 & 12.599 & 6.657 & 5.639 & 21.345 & 9.773 & 21.043 \\
\hline \multirow{3}{*}{530} & 0.08 & 0.545 & 3.09 & 1.747 & 1.352 & 0.661 & 4.113 & 2.213 & 3.796 \\
\hline & 0.19 & 1.194 & 5.937 & 3.514 & 2.423 & 1.431 & 6.966 & 5.22 & 6.54 \\
\hline & 0.37 & 4.936 & 19.479 & 12.72 & 6.759 & 5.664 & 21.94 & 9.663 & 21.643 \\
\hline \multirow{3}{*}{660} & 0.08 & 0.610 & 3.396 & 1.846 & 1.550 & 0.741 & 4.283 & 2.17 & 3.836 \\
\hline & 0.19 & 1.198 & 5.986 & 3.593 & 2.392 & 1.439 & 7.233 & 5.23 & 6.796 \\
\hline & 0.37 & 4.906 & 19.461 & 12.809 & 6.651 & 5.637 & 22.143 & 9.076 & 21.463 \\
\hline \multicolumn{2}{|c|}{$\rho$} & 0.96 & 0.96 & 0.96 & 0.97 & 0.96 & 0.97 & 0.98 & 0.97 \\
\hline \multicolumn{2}{|c|}{$t[\%]$} & $201 \%$ & $172 \%$ & $184 \%$ & $153 \%$ & $197 \%$ & $158 \%$ & $138 \%$ & $166 \%$ \\
\hline
\end{tabular}

Analyzing presented tests results and roughness measurements it can be stated that according to theory along with increasing of feed all basic amplitude roughness parameters, both classic ones and those of group of motifs also increased. Level of correlation coefficient in each case was greater than 0.96 and indicator $t$ oscillated between 138-201\%, which clearly indicates good description of the relevance of changes in the profile by these parameters.

Statistical parameters such as skewness $R s k$ and kurtosis $R k u$, showed insufficiently high linear correlation with feed. In their case indicator $t$ assumed values greater than limit of $30 \%$, however they were smaller than in case of the amplitude parameters.

Along with increasing feed, change of spatial parameters $R S m$ and $R S$ was also observed. This indicates a change in the distance between successive profile peaks as well as about increasing width of profile valleys. Linear correlation coefficient assumed for them values greater than 0,95 whereas indicator $t$ higher than $154 \%$. 
Table 2. Influence of the feed $f$ on values of selected spatial, statistical and hybrid roughness parameters $2 \mathrm{D}$

\begin{tabular}{|c|c|c|c|c|c|c|c|c|}
\hline \multirow{2}{*}{\multicolumn{2}{|c|}{ Machining parameters }} & \multicolumn{7}{|c|}{ Roughness parameters } \\
\hline & & \multicolumn{2}{|c|}{ STATISTICAL } & \multicolumn{2}{|c|}{ SPATIAL } & \multirow{2}{*}{$\begin{array}{c}\text { MOTIF } \\
A R\end{array}$} & \multicolumn{2}{|c|}{ HYBRID } \\
\hline $\begin{array}{c}v_{c} \\
{\left[\mathrm{~m} \cdot \mathrm{min}^{-1}\right]}\end{array}$ & $\begin{array}{c}f \\
{\left[\mathrm{~mm} \cdot \mathrm{rev}^{-1}\right]}\end{array}$ & $R k u$ & Rsk & $R S m$ & $R S$ & & $R \triangle a$ & $R \Delta q$ \\
\hline \multirow{3}{*}{105} & 0.08 & 2.313 & 0.075 & 60.686 & 16.93 & 85.133 & 5.83 & 7.33 \\
\hline & 0.19 & 2.232 & 0.290 & 180.23 & 36.983 & 176.133 & 5.426 & 7.106 \\
\hline & 0.37 & 2.07 & 0.655 & 364.516 & 192.89 & 171.533 & 7.116 & 8.81 \\
\hline \multirow{3}{*}{210} & 0.08 & 2.766 & 0.205 & 67.726 & 17.5 & 88.8 & 6.053 & 7.69 \\
\hline & 0.19 & 2.360 & 0.429 & 187.21 & 36.03 & 183 & 5.526 & 7.35 \\
\hline & 0.37 & 2.033 & 0.6407 & 373.146 & 200.44 & 179.3 & 7.153 & 8.86 \\
\hline \multirow{3}{*}{420} & 0.08 & 3.467 & 0.563 & 71.733 & 17.91 & 90.9 & 5.756 & 7.533 \\
\hline & 0.19 & 9.734 & 0.993 & 79.78 & 18.206 & 87.8 & 5.943 & 7.676 \\
\hline & 0.37 & 2.085 & 0.663 & 373.496 & 209.873 & 178 & 7.243 & 9.01 \\
\hline \multirow{3}{*}{530} & 0.08 & 2.504 & 0.346 & 58.103 & 16.603 & 85.57 & 6.366 & 7.99 \\
\hline & 0.19 & 2.398 & 0.415 & 179.62 & 36.656 & 183.47 & 5.69 & 7.686 \\
\hline & 0.37 & 2.09 & 0.661 & 365.643 & 292.283 & 175.83 & 7.203 & 9.003 \\
\hline \multirow{3}{*}{660} & 0.08 & 2.384 & 0.174 & 64.95 & 17.413 & 86.36 & 6.213 & 7.823 \\
\hline & 0.19 & 2.439 & 0.469 & 177.073 & 39.133 & 182.45 & 5.586 & 7.663 \\
\hline & 0.37 & 2.117 & 0.6811 & 372.566 & 245.6 & 163.07 & 7.173 & 9.003 \\
\hline \multicolumn{2}{|c|}{$\rho$} & -0.83 & 0.81 & 0.99 & 0.95 & 0.77 & 0.78 & 0.87 \\
\hline \multicolumn{2}{|c|}{$t[\%]$} & $45 \%$ & $102 \%$ & $154 \%$ & $226 \%$ & $67 \%$ & $25 \%$ & $18 \%$ \\
\hline
\end{tabular}

Remaining parameters including the only spatial parameter from the motif group and hybrid parameters $R \Delta a$ and $R \Delta q$ due to low level of calculated significance indicators were considered to be slightly dependent on the feed value. By analyzing tests results configured by constant feed and variable cutting speed (Table 3 and 4 ) it can be seen that no parameter has shown sufficient correlation with cutting speed $v_{c}$. For none of the parameters correlation coefficient above 0,9 was not obtained. The highest value was obtained for $R \Delta q$ parameter and it was at 0.86 . For all parameters apart hybrid, values of indicator $t$ higher than $30 \%$ were obtained however when linear correlation coefficients were too low. It can be concluded that influence of the cutting speed on surfaces features cannot be described by these parameters.

Table 3. Influence of the cutting speed $v_{c}$ on the values of selected amplitude roughness parameters $2 \mathrm{D}$

\begin{tabular}{|c|c|c|c|c|c|c|c|c|c|}
\hline \multirow{2}{*}{\multicolumn{2}{|c|}{ Roughness parameters }} & \multicolumn{8}{|c|}{ Roughness parameters } \\
\hline & & \multicolumn{5}{|c|}{ AMPLITUDE } & \multicolumn{3}{|c|}{ MOTIF } \\
\hline $\begin{array}{c}v_{c} \\
{\left[\mathrm{~m}_{\mathrm{min}}^{-1}\right]}\end{array}$ & $\begin{array}{c}f \\
{\left[\mathrm{~mm}_{\mathrm{rev}}^{-1}\right]}\end{array}$ & $R a$ & $R z$ & $R p$ & $R v$ & $R q$ & $P t$ & $R$ & $R x$ \\
\hline \multirow{5}{*}{0.08} & 105 & 0.53 & 2.989 & 1.569 & 1.42 & 0.642 & 3.863 & 1.95 & 3.21 \\
\hline & 210 & 0.551 & 3.353 & 1.862 & 1.494 & 0.674 & 4.14 & 2.23 & 3.84 \\
\hline & 420 & 0.521 & 3.399 & 2.030 & 1.368 & 0.643 & 5.47 & 2.16 & 4.41 \\
\hline & 530 & 0.545 & 3.099 & 1.747 & 1.352 & 0.661 & 4.113 & 2.213 & 3.796 \\
\hline & 660 & 0.610 & 3.396 & 1.846 & 1.552 & 0.741 & 4.283 & 2.17 & 3.836 \\
\hline
\end{tabular}




\begin{tabular}{|c|c|c|c|c|c|c|c|c|c|}
\hline \multirow{5}{*}{0,19} & 105 & 1.183 & 5.89 & 3.298 & 2.598 & 1.407 & 6.82 & 4.796 & 6.276 \\
\hline & 210 & 1.167 & 5.688 & 3.412 & 2.276 & 1.376 & 7.13 & 5.25 & 6.83 \\
\hline & 420 & 0.559 & 3.564 & 2.112 & 1.459 & 0.713 & 6.89 & 2.116 & 5.813 \\
\hline & 530 & 1.194 & 5.937 & 3.514 & 2.421 & 1.431 & 6.966 & 5.2 & 6.5 \\
\hline & 660 & 1.198 & 5.986 & 3.593 & 2.397 & 1.439 & 7.233 & 5.23 & 6.796 \\
\hline \multirow{5}{*}{0,37} & 105 & 4.946 & 19.235 & 12.414 & 6.829 & 5.667 & 21.976 & 9.436 & 21.076 \\
\hline & 210 & 4.981 & 18.966 & 12.243 & 6.723 & 5.694 & 21.97 & 9.85 & 21.58 \\
\hline & 420 & 4.917 & 19.256 & 12.599 & 6.654 & 5.639 & 21.34 & 9.77 & 21.043 \\
\hline & 530 & 4.936 & 19.479 & 12.72 & 6.751 & 5.664 & 21.94 & 9.663 & 21.643 \\
\hline & 660 & 4.906 & 19.461 & 12.809 & 6.659 & 5.637 & 22.143 & 9.076 & 21.463 \\
\hline & -0.05 & 0.4 & 0.48 & -0.23 & -0.02 & 0.29 & 0.04 & 035 \\
\hline \multicolumn{2}{|c|}{$t[\%]$} & $81 \%$ & $65 \%$ & $85 \%$ & $73 \%$ & $75 \%$ & $54 \%$ & $107 \%$ & $56 \%$ \\
\hline
\end{tabular}

Additionally correlation between classical parameters and those from motif group was checked. Such dependence or independence of parameters is very important and plays (or may play) decisive role in selection of identification method and describing geometrical surfaces features. In a situation when two parameters are strongly dependent from each other they can be treated as a complement of main indicator used for description a given feature of parameter. As the main indicator ideal for describing given feature such parameter should be chosen that is absolutely independent of others because only in such case its values can be determined in unequivocally and objective way.

Table 5 shows linear correlation coefficient between classical amplitude parameters, hybrid ones and from motif group. Table 6 shows correlation between spatial parameters and parameter AR from motif group.

Analyzing data given in tables it can be stated that close dependence and correlation is between parameters $P t, R x$ and $R$ from the motif group of parameters and amplitude parameters at the lack of close connection with statistical and hybrid parameters.

Table 4. Influence of cutting speed $v_{c}$ on selected values of spatial, statistical and hybrid roughness parameters $2 \mathrm{D}$

\begin{tabular}{|c|c|c|c|c|c|c|c|c|}
\hline \multirow{2}{*}{\multicolumn{2}{|c|}{ Cutting speed }} & \multicolumn{7}{|c|}{ Roughness parameters } \\
\hline & & \multicolumn{2}{|c|}{ STATISTICAL } & \multicolumn{2}{|c|}{ SPATIAL } & \multirow{2}{*}{$\frac{\text { MOTIF }}{A R}$} & \multicolumn{2}{|c|}{ HYBRID } \\
\hline $\begin{array}{c}v_{c} \\
{\left[\mathrm{~m} \cdot \mathrm{min}^{-1}\right]}\end{array}$ & $\begin{array}{c}f \\
{\left[\mathrm{~mm}^{\prime} \cdot \mathrm{rev}^{-1}\right]}\end{array}$ & $R k u$ & Rsk & $R S m$ & $R S$ & & $R \Delta a$ & $R \Delta q$ \\
\hline \multirow{5}{*}{0.08} & 105 & 2.313 & 0.075 & 60.686 & 16.93 & 85.133 & 5.83 & 7.33 \\
\hline & 210 & 2.766 & 0.205 & 67.726 & 17.5 & 88.8 & 6.053 & 7.69 \\
\hline & 420 & 3.467 & 0.563 & 71.733 & 17.91 & 90.9 & 5.756 & 7.533 \\
\hline & 530 & 2.504 & 0.346 & 58.103 & 16.603 & 85.57 & 6.366 & 7.99 \\
\hline & 660 & 2.384 & 0.174 & 64.95 & 17.413 & 86.3 & 6.213 & 7.823 \\
\hline \multirow{5}{*}{0.19} & 105 & 2.232 & 0.29 & 180.23 & 36.983 & 176.133 & 5.426 & 7.106 \\
\hline & 210 & 2.36 & 0.429 & 187.21 & 36.03 & 183 & 5.526 & 7.353 \\
\hline & 420 & 9.734 & 0.993 & 79.78 & 18.206 & 87.8 & 5.943 & 7.676 \\
\hline & 530 & 2.398 & 0.415 & 179.62 & 36.656 & 183.4 & 5.69 & 7.686 \\
\hline & 660 & 2.439 & 0.469 & 177.073 & 39.133 & 182.4 & 5.586 & 7.663 \\
\hline
\end{tabular}




\begin{tabular}{|c|c|c|c|c|c|c|c|c|}
\hline \multirow{4}{*}{0.37} & 105 & 2.07 & 0.655 & 364.516 & 192.89 & 171.533 & 7.116 & 8.81 \\
\cline { 2 - 10 } & 210 & 2.033 & 0.64 & 373.146 & 200.44 & 179.3 & 7.153 & 8.86 \\
\cline { 2 - 9 } & 420 & 2.085 & 0.663 & 373.496 & 209.873 & 178 & 7.243 & 9.01 \\
\cline { 2 - 9 } & 530 & 2.09 & 0.661 & 365.643 & 292.28 & 175.83 & 7.203 & 9.003 \\
\cline { 2 - 9 } & 660 & 2.117 & 0.681 & 372.566 & 245.6 & 163.07 & 7.173 & 9.003 \\
\hline \multicolumn{2}{|c|}{$\rho$} & 0.32 & 0.49 & 0.05 & 0.27 & -0.18 & 0.56 & 0.86 \\
\hline \multicolumn{2}{|c|}{$t[\%]$} & $251 \%$ & $332 \%$ & $95 \%$ & $201 \%$ & $93 \%$ & $25 \%$ & $23 \%$ \\
\hline
\end{tabular}

Table 5. Matrix of correlation coefficients for amplitude, hybrid and motif roughness parameters

\begin{tabular}{|c|c|c|c|c|c|c|c|c|c|}
\hline & $R a$ & $R z$ & $R p$ & $R v$ & $R q$ & $R k u$ & $R s k$ & $R \Delta a$ & $R \Delta q$ \\
\hline$R a$ & 1 & & & & & & & & \\
\hline$R z$ & 0.9995 & 1 & & & & & & & \\
\hline$R p$ & 0.9991 & 0.9998 & 1 & & & & & & \\
\hline$R v$ & 0.9987 & 0.9990 & 0.9978 & 1 & & & & & \\
\hline$R q$ & 1.0000 & 0.9996 & 0.9993 & 0.9989 & 1 & & & & \\
\hline$R k u$ & -0.3367 & -0.3307 & -0.3223 & -0.3475 & -0.3343 & 1 & & & \\
\hline$R s k$ & 0.5267 & 0.5373 & 0.5462 & 0.5182 & 0.5296 & 0.5309 & 1 & & \\
\hline$R \Delta a$ & 0.8932 & 0.8854 & 0.8900 & 0.8746 & 0.8920 & -0.2324 & 0.4603 & 1 & \\
\hline$R \Delta q$ & 0.9269 & 0.9237 & 0.9288 & 0.9119 & 0.9266 & -0.2399 & 0.5424 & 0.9775 & 1 \\
\hline$P t$ & 0.9957 & 0.9964 & 0.9970 & 0.9937 & 0.9960 & -0.2584 & 0.5990 & 0.8864 & 0.9250 \\
\hline$R$ & 0.9657 & 0.9687 & 0.9657 & 0.9736 & 0.9664 & -0.3971 & 0.5010 & 0.7653 & 0.8367 \\
\hline$R x$ & 0.9974 & 0.9979 & 0.9984 & 0.9956 & 0.9977 & -0.2780 & 0.5830 & 0.8884 & 0.9275 \\
\hline
\end{tabular}

Some observed relations are obvious. For example relation $P t-R z$ results from their definition $-P t$ refers to the primary profile, and $R z$ refers to roughness profile. In $2 \mathrm{D}$ system their dependence is defined as $P t=1.27 R z$. Equally high correlation occurs between parameters $R x$ and $R z$. Their dependence was calculated as $R x=1.17 R z$.

The only spatial parameter from motif group showed independence from classical parameters. Correlation between $A R$, spatial and hybrid parameters is less than 0.78 .

Table 6. Matrix of correlation coefficients for spatial roughness parameters and from motif group

\begin{tabular}{|c|c|c|c|c|}
\hline & $R S m$ & $R S$ & $R \Delta a$ & $R \Delta q$ \\
\hline$R S m$ & 1 & & & \\
\hline$R S$ & 0.937385076 & 1 & & \\
\hline$R \Delta a$ & 0.774039748 & 0.891210473 & 1 & \\
\hline$R \Delta q$ & 0.841180807 & 0.925931889 & 0.977547659 & 1 \\
\hline$A R$ & 0.8500291 & 0.570359323 & 0.248876757 & 0.384685697 \\
\hline
\end{tabular}




\section{Summary}

- For evaluation of usefulness of individual roughness parameters for description geometric changes of surface layer and geometric state of the surface not only correlation coefficient $\rho$ should be taken into account but also $t$ indicator determining the level of significance of change in characteristic profile feature. Applying of two indicators will allow for more complete assessment of parameters usefulness.

- Use of the parameters from the group of motifs for description of the surface with oriented periodic character is possible and may complement description of this type of surfaces carried out with using parameters described in ISO standards.

- For amplitude parameters best describing surface characterized by features resulting from variable feed during machining include: $R a, R z, R p, R v, R q$ and motif parameters: $P t, R x, R$.

- Spatial parameters that describes in best way surface characterized by features resulting from variable feed may be $R S m$ and $R S$. The only motif parameter from that group: $A R$ despite the value of indicator $t$ equal $67 \%$, due to low correlation does not describe all changes of surface geometrical features.

- Due to the close dependence (regardless of turning parameters) of $P t$ and $R z$ parameters as well as $R x$ and $R z$ it seems unreasonable using all three of them simultaneously.

- Hybrid parameters: $R \Delta a$ and $R \Delta q$ and statistical: $R k u$ and $R s k$ do not show sufficiently strong relations with feed and cutting speed, therefore it is not advisable to describe the state of geometric structure of surface by themselves.

The article was made under support grant project KEGA 022ŽU-4/2017 Implementation of on-line education in the area of precise technologies with an impact on educational process to increase skills and flexibility of students of engineering fields of study

\section{References}

1. M. Wieczorowski, A. Cellary, J. Chajda, Przewodnik po pomiarach nierówności powierzchni czyli o chropowatości i nie tylko. Zakład Poligraficzno - Wydawniczy M - Druk. Poznań (2003)

2. K.J. Stout, L. Blunt,: A contribution to the debate on surface classifications - random, systematic, unstructured, structured and engineering. International Journal of Machine Tools \& Manufacture, 41, 2039-2044, (2001)

3. K.E. Oczoś, V. Liubimov, Struktura geometryczna powierzchni. Podstawy klasyfikacji $z$ atlasem charakterystycznych powierzchni ksztaltowanych. Oficyna Wydawnicza Politechniki Rzeszowskiej, Rzeszów (2003)

4. P. Pawlus, Struktura geometryczna powierzchni cylindrów podczas eksploatacji silnika spalinowego. Oficyna Wydawnicza Politechniki Rzeszowskiej, Rzeszów (1999)

5. S. Lou, X. Jiang, P. J. Scott, Correlating motif analysis and morphological filters for surface texture analysis. Measurement 46 993-1001, (2013)

6. W. Grzesik, J.Rech, K. Żak, High-Precision Finishing Hard Steel Surfaces Using Cutting, Abrasive and Burnishing Operations. Procedia Manufacturing Volume 1, 619-627 (2015)

7. A. Rudawska, M. Reszka, T. Warda, I. Miturska, J. Szabelski, A. Skoczylas, D. Stancekova, Milling as a method of surface pre-treatment of steel for adhesive bonding. J. Adhes. Sci. Technol., 23, 2619-2636 (2016)

8. M. Kowalski: Metodyka wyboru parametrów chropowatości do opisu topografii powierzchni. Politechnika Wrocławska, Instytut Technologii Maszyn i Automatyzacji, Wrocław (2005) 